\title{
CONSERVAÇÃO DE PEÇAS ANATÔMICAS: VANTAGENS E DESVANTAGENS DE DIFERENTES MÉTODOS
}

\section{CONSERVATION OF ANATOMICAL PARTS: ADVANTAGES AND DISADVANTAGES OF DIFFERENT METHODS}

\begin{abstract}
Elisama Lima Lara Fontoura1*, Sônia Trannin de Mello², Célia Regina de Godói Gomes $^{3}$, Josiane Medeiros de Mello ${ }^{4}$

${ }^{1}$ Enfermeira - Especialista em Anatomia e Histologia pela Universidade Estadual de Maringá.

${ }^{2}$ Enfermeira - Prof $^{a}$ Dr $^{a}$ do Departamento de Ciências Morfológicas - Universidade Estadual de Maringá.

${ }^{3}$ Fisioterapeuta - Profa ${ }^{a} r^{a}$ do Departamento de Ciências Morfológicas - Universidade Estadual de Maringá.

${ }^{4}$ Bióloga - Prof ${ }^{a}$ Dra do Departamento de Ciências Morfológicas - Universidade Estadual de Maringá.

* Universidade Estadual de Maringá (UEM), Centro de Ciências Biológicas - CCB, Departamento de Ciências Morfológicas - DCM, Bloco H-79, Av. Colombo 5970 - Zona 07 - CEP 87020-900 Maringá - PR. E-mail: elisamalara@hotmail.com
\end{abstract}

Submetido em: 04/06/2019; Aceito em: 19/05/2020.

\section{RESUMO}

A Anatomia Humana é a ciência que estuda a composição e a morfologia do corpo humano, ela nomeia e descreve suas estruturas em níveis macro e microscópicos. Os objetivos do presente estudo consistem em descrever métodos de conservação de tecidos biológicos humanos, com ênfase às técnicas de formolização, glicerinação, criodesidratação e plastinação, utilizadas para o estudo da anatomia humana, destacando suas vantagens e desvantagens. Foi realizado um estudo descritivo por meio de um levantamento bibliográfico dos artigos publicados nas bases virtuais BIREME, Scielo, Lilacs e PubMed, do período de 2007 a 2017. Os resultados mostram que a maioria das instituições de ensino ainda utiliza a formolização como técnica padrão na conservação das peças anatômicas, por ser, financeiramente, a mais vantajosa, porém, com relação às demais técnicas, a que melhor apresenta uma relação custo/benefício é a glicerinação, pois apresenta maiores vantagens em relação à saúde da pessoa exposta e ao meio ambiente, por ter uma toxicidade consideravelmente menor em relação ao formol. A criodesidratação também consiste em uma alternativa viável ao uso do formaldeído, para isto, ela deve ser mais difundida no meio acadêmico. Quanto à plastinação, esta ainda é uma alternativa para exposições de peças em museus, devido ao seu alto custo. Portanto, a técnica mais indicada atualmente para o estudo da Anatomia é a glicerinação, nas demais técnicas apresentadas, as desvantagens acabam por inviabilizar e dificultar o seu uso para conservação dos tecidos biológicos.

Palavras-chave: Anatomia. Cadáver. Materiais de Estudo. Metodologia. 


\section{ABSTRACT}

The Human anatomy is the science that studies the composition and morphology of the human body, it names and describes its structures at macro and microscopic levels. The objectives of this study are describe methods of conservation of human biological tissue, with emphasis on the techniques of formaldehyde, glycerination, cryodeshydration and plastination, used to study the human anatomy, highlighting its advantages and disadvantages. Was performed a descriptive study by means of a bibliographical survey of the articles published in the BIREME, Scielo, Lilacs and PubMed virtual databases from 2007 to 2017. The results show that most of the educational institutions still use formaldehyde with a standard technique in the conservation of the anatomical parts, for being, financially, the most advantageous, however, in relation to other techniques, the that best features a cost / benefit ratio is glycerin because it presents greater advantages in relation to the health of the exposed person and to the environment, for better an toxicity considerably lower with respect to formaldehyde. The creodehydration also consists in a viable alternative to the use of formaldehyde, for this, she must be more widespread in academia. As to plastination, this is still an alternative to exhibits of parts in museum because of its high cost. Therefore, the technique more indicated currently for the study of anatomy is glycerination, in the other techniques presented, the disadvantages end up unfeasible and difficult to use for conservation of biological tissues.

Keywords: Anatomy. Cadaver. Methodology. Study Materials.

\section{INTRODUÇÃO}

A anatomia humana é a ciência que estuda a composição e a morfologia do corpo humano, ela nomeia e descreve suas estruturas aos níveis macro e microscópicos; é uma disciplina tradicional dos cursos da área da Saúde, básica para a formação de todo o profissional desta (DANGELO; FATTINI, 2007). O conhecimento sobre a forma e o funcionamento do corpo humano é um assunto de amplo interesse, que abrange tanto os profissionais das áreas biológicas e da saúde quanto os estudantes de qualquer nível de escolaridade (MELLO et al., 2010).

Aulas práticas de anatomia em peças cadavéricas, sempre foram valorizadas pelo professor e pelo estudante (BAPTISTA et al., 2012). As práticas aproximam os alunos da teoria e os auxiliam na construção dos conceitos e na consolidação do aprendizado (AVERSI-FERREIRA et al., 2009).

O primeiro registro do estudo da anatomia humana é datado de 1552 a.C., está contido no papiro Ebers, um documento médico com 110 páginas escrito na época do antigo Egito, o qual faz uma descrição precisa do sistema circulatório, com menção da existência de vasos sanguíneos por todo o corpo e o funcionamento cardíaco como centro do suprimento sanguíneo, porém, na maior parte, estes escritos eram baseados no imaginário dos egípcios, algum aprendizado na prática iniciou-se com a mumificação (SOUZA, 2011).

A mumificação era uma maneira empírica por meio da qual os egípcios realizavam a conservação do corpo como um todo. A prática da conservação de 
corpos desenvolveu-se no século XVI com as técnicas de embalsamento papal e vêm evoluindo com a formolização, a glicerinização, entre outras, até as técnicas mais recentes como a plastinação (TAVANO; OLIVEIRA, 2008; ANDREOLI et al., 2012).

As técnicas mais conhecidas são a formolização e a glicerinização e, de acordo com Silva et al. (2016), em um estudo realizado com professores da área de anatomia humana em 242 faculdades de Medicina do Brasil, 96\% das faculdades utilizam cadáveres humanos para o estudo desta disciplina, uso este que é regulamentado de acordo com a Lei 8501/92; destas, 83,3\% realizam a conservação das peças com o uso da formolização e 56,4\% fazem uso da glicerinização.

A aquisição de novas peças cadavéricas é cada dia um obstáculo maior ao estudo da anatomia humana no Brasil, onde, há séculos, utiliza-se do cadáver humano como material de ensino. O material humano, além de difícil aquisição, é ameaçado por dificuldades no âmbito jurídico, religioso, moral e, principalmente, pela falta de conscientização da sociedade sobre a importância da doação de cadáveres para fins de estudo e da realização de pesquisas de cunho científico. Diante deste fato, a alternativa é investir em métodos de conservação cada vez mais eficazes e que causem um menor dano ao material estudado (BRASIL, 1992; QUEIROZ, 2005; MELO; PINHEIRO, 2010).

O presente estudo tem como objetivo descrever métodos de conservação de tecidos biológicos humanos, com ênfase às técnicas de formalização, glicerinização, criodesidratação e plastinação utilizadas para o estudo da anatomia humana e animal. Serão apresentadas as vantagens e desvantagem de cada método, visando atender as necessidades das instituições de ensino, dos docentes e dos estudantes quanto ao melhor método a ser utilizado, frente à realidade específica de cada caso.

\section{METODOLOGIA}

Foi realizado um estudo descritivo, desenvolvido a partir de um levantamento bibliográfico dos artigos publicados nas bases de dados virtuais BIREME, Scielo, Lilacs e PubMed, no período de 2007 a 2017.

Foram utilizados os descritores listados no DeCS - Anatomia (descrito como "ramo da biologia que lida com a estrutura dos organismos"), Materiais de Estudo (termo geral, sem descrição detalhada no DeCS), Cadáver (descrito como "corpo morto, geralmente corpo humano") e Metodologia (descrito como "trabalhos sobre estudos que determinam a efetividade ou o valor dos processos, pessoal e equipamento, ou o material na condução destes estudos") - em Português, assim como seus similares em Inglês e Espanhol para a localização de artigos relevantes ao tema com pesquisa dos descritores individualmente ou em pares utilizando-se da palavra "and" entre os descritores.

Os artigos selecionados foram em Português, Inglês e Espanhol que realizavam uma descrição das técnicas, comparação entre diferentes técnicas e análise das peças produzidas com data de publicação entre 2007 a 2017. Artigos com data de publicação em anos anteriores a 2007, assim como os que não realizavam a análise e descrição da técnica ou das peças produzidas foram excluídos. 


\section{DESENVOLVIMENTO}

Para estudo da anatomia humana, o corpo humano passa pelo ato de preservação dos tecidos biológicos, evitando assim, a sua decomposição por agentes químicos, físicos e biológicos. A função da fixação é manter os tecidos, preservando-os para realização de estudos. É importante analisar que, para uma fixação adequada, deve-se considerar o pequeno intervalo entre a morte e a fixação, o contato do fixador com todo tecido, o volume do fixador, que deve ser de vinte vezes o volume da peça anatômica e a escolha adequada do fixador (RODRIGUES, 2010; CURY; CENSONI; AMBROSIO, 2013).

As técnicas de conservação utilizadas em anatomia, tanto humana quanto animal, tem a finalidade de preservar as características morfológicas das peças quanto à coloração, consistência e flexibilidade dos tecidos, ademais, também evita a deterioração, o que faz com que os tecidos permaneçam firmes e insolúveis (RODRIGUES, 2010).

$\mathrm{Na}$ bibliografia levantada foram avaliadas as quatro diferentes técnicas considerando entre outros aspectos, os critérios de utilidade da peça anatômica, custo de preparação, manutenção, tempo de preparo, durabilidade e toxicidade, além das vantagens e desvantagens de cada técnica apresentada.

A Formolização (Figura 1) é o método mais frequente entre as universidades, esta utiliza o formaldeído que, quando diluído, denomina-se formol, sua concentração varia entre 3 a $20 \%$, a concentração mais utilizada é a de $10 \%$. Seu uso em grande abrangência dá-se por ser uma técnica de simples realização e boa penetração nos tecidos, pelo fato de evitar a proliferação de microrganismos e patógenos e também impedir a deterioração do material. Como vantagens pode-se apresentar também o baixo custo para sua utilização, pois, o formaldeído é adquirido em concentração de 37\% e custa em torno de $\mathrm{R} \$ 3,50$ por litro, após a diluição para a concentração desejada, seu custo pode chegar à $\mathrm{R} \$ 0,52$ por litro, além disso, o uso da peça anatômica conservada em formaldeído proporciona um adequado conhecimento de anatomia aos estudantes, devido à perfeita evidenciação da anatomia externa e interna das peças estudadas (CURY; CENSONI; AMBROSIO, 2013; OLIVEIRA et al., 2013; SPAZIANI et al., 2016).

Com relação à manutenção, para as peças fixadas em formol, segundo Paim, Toillier e Bartholdy (2017), exige-se reposição quinzenal da solução conservadora na qual as peças são mantidas, quando da utilização constante destas. É importante ressaltar que, para usar a peça anatômica conservada em formol, é comum a passagem da mesma em água para diminuir o odor forte do formol e ainda exige-se que o material seja molhado até três vezes ao dia, com água para não haver a secagem das estruturas anatômicas. Nesse processo de lavagem retira-se parte do fixador, o que exige uma posterior reposição do formol de modo que essa reposição varia de acordo com a utilização da peça anatômica. A técnica de formolização é de fácil manutenção, pois exige apenas reposição do agente químico formaldeído e tem sua vida útil relativamente longa, se manipuladas de maneira correta a fim de evitar a destruição dos tecidos (SPAZIANI et al., 2016). 
Entre as suas desvantagens está o efeito destrutivo nos tecidos em nível morfológico e em seu DNA, segundo estudos citados por Carvalho (2009), este efeito em nível morfológico pode alterar pequenas estruturas e esta alteração faz com que o cadáver, depois de conservado em formol, não possa ser identificado por meio de seu DNA. Ainda, pode-se evidenciar o forte odor, o qual causa irritação das mucosas; o alto nível de contaminação ao meio ambiente e a elevada toxicidade; além disso, o formol, ao ter contato com as peças, faz com que as mesmas fiquem friáveis e de difícil utilização devido ao fato de que o seu peso aumenta pelo acúmulo da substância de conservação, pois as peças precisam ser mantidas em solução aquosa conservadora (CARVALHO, 2009; CURY; CENSONI; AMBROSIO, 2013; OLIVEIRA et al., 2013).

O formaldeído também tem sido descrito como cancerígeno pelo Programa Nacional de Toxicologia dos Estados Unidos (NTP, 2010). A absorção do formaldeído inalado por humanos ocorre $90 \%$ no trato respiratório superior, porém, este também penetra via derme e é classificado como um produto carcinogênico para os seres humanos (VIEGAS et al., 2010). Esta substância foi listada pela primeira vez como cancerígena no Segundo Relatório Anual sobre Carcinogênicos, publicado no ano de 1981, com a previsão de que fosse uma substância carcinogênica para humanos com base em evidências de estudos realizados com animais, desde então, estudos sobre o câncer em humanos foram publicados e o status do formaldeído na lista foi alterado para carcinogênico humano no Décimo Segundo Relatório sobre Carcinogênicos, publicado no ano de 2011 (NTP, 2016).

A Glicerinização (Figura 1) utiliza a glicerina (nome comercial) para designar um produto que diz respeito à substância glicerol, um composto orgânico pertencente à função álcool, que se apresenta de forma líquida à temperatura ambiente $\left(25^{\circ} \mathrm{C}\right)$, higroscópico - possui capacidade de absorver a umidade do ar, inodoro, viscoso e de sabor adocicado (SILVA et al., 2008). Para Rodrigues (2010), a descoberta da glicerina como fixador representou um grande avanço na preparação dos materiais anatômicos, pois a glicerina tem baixa toxicidade oral e dérmica e atua muito bem na conservação dos tecidos biológicos, evitando o ataque por fungos e bactérias. Além da glicerina possuir função fungicida e bactericida, as peças apresentam-se com mais leveza e estas possuem um longo período de utilização se conservadas corretamente, além da perfeita visualização das estruturas anatômicas externas e internas.

Como desvantagem a técnica de glicerinização apresenta um custo inicial, pouco mais elevado que o formol, em torno de $R \$ 5,36$ por litro para a sua utilização e é necessário manter a peça em solução conservadora, o que traz maior dificuldade na limpeza e manutenção das macas que ficam sujas ao trocar o material de uma maca para outra, além disso, a glicerina constitui um produto eficaz para conservação, porém, não para fixação, portanto, é necessário fixar a peça em formol a $10 \%$ antes de conservá-la em glicerina. A reposição da glicerina depende da utilização do material, pois quanto maior o uso, ocorre maior perda de material que, mesmo em quantidades pequenas, deve ser reposto em uma frequência mensal, ou, quando observado o ressecamento do material anatômico (CURY; CENSONI; AMBROSIO, 2013; SPAZIANI et al., 2016). 
Figura 1 - Encéfalos em corte frontal.

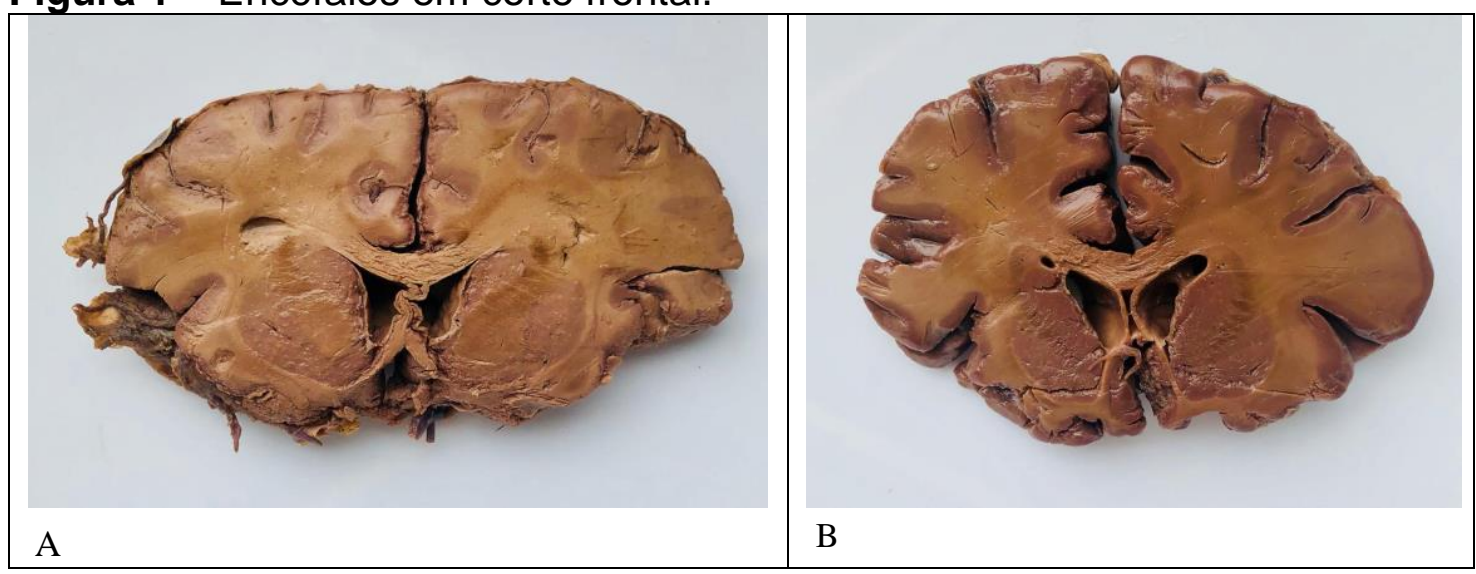

Notas: Em A: conservado com formalização e em B: conservado com Glicenirização. Acervo do Departamento de Ciências Morfológicas da Universidade Estadual de Maringá.

Fonte: os autores.

Outra técnica utilizada é a criodesidratação (Figura 2), técnica que desidrata peças por meio do congelamento e descongelamento repetitivo e excessivo para que seja retirada toda a água do material a ser estudado. Esta técnica é indicada para conservação de peças individuais e animais inteiros, não indicada para conservação de cadáver de modo inteiro. Esta técnica surgiu na tentativa de sanar os problemas da conservação e manutenção de peças anatômicas em formol descritos acima. No estudo realizado por Cury, Censoni e Ambrósio (2013) as peças submetidas a esta técnica foram ventrículos gástricos de diferentes espécies de animais, estes foram retirados dos animais de modo a deixar preservados alguns centímetros do esôfago e do duodeno. Após a dissecção foi injetado ar nas peças dissecadas com a extremidade do duodeno de cada peça amarrada de modo a impedir a saída do ar e, após inflado, amarrado a extremidade do esôfago. Após inflados, os órgãos foram levados a um container refrigerado a temperatura abaixo de $8^{\circ} \mathrm{C}$ (graus Celsius), as peças foram mantidas por 48 horas em congelamento e em seguida, 24 horas a temperatura ambiente. Foi repetido este revezamento por seis a oito vezes. A cada descongelamento, cada peça era inflada com ar novamente e, ao finalizar, as peças foram mantidas fechadas.

As vantagens desta técnica consistem em não ser necessário manter a peça em solução conservadora; além da leveza da peça, devido ao fato de não conter água, o material fica extremamente leve, o que facilita o transporte e manuseio. $O$ fato das peças serem conservadas com coloração muito próxima ao natural torna o material de estudo mais didático. Como vantagens ao método também destaca-se o baixo custo para sua realização, pois o gasto para realização desta técnica depende do valor da tarifa de energia local, pois é necessário somente o congelamento e descongelamento repetitivo das peças, porém, os autores que a descrevem relatam que é a técnica com o custo de preparação mais baixo. Quanto á manutenção, a criodesidratação não exige reposição de substância por não ser necessário manter a peça em solução conservadora (KREMER; SCHUBERT; BONFIGLIO, 2011; CURY; CENSONI; AMBROSIO, 2013; SILVA et al., 2013). 
Como desvantagens, a criodesidratação apresenta a demora na preparação, além da técnica causar uma inevitável retração dos tecidos devido à total perda de água, porém, não é considerado fator agravante desde que, se a peça for para fins acadêmicos, seja evidenciado ao aluno que a mesma está deformada devido ao método utilizado para sua conservação; além disso, podese citar a fragilidade das peças a possíveis quedas e movimentações bruscas, pois, devido à ausência de água nos tecidos e estruturas as peças ficam mais rígidas e frágeis e com maior probabilidade de rompimento; pode-se citar também a possibilidade de corrosão por insetos, como a traça e outros, devido à esta fragilidade as peças preparadas com esta técnica são mais destinadas a exposições em museus (KREMER; SCHUBERT; BONFIGLIO, 2011; CURY; CENSONI; AMBROSIO, 2013; SILVA et al., 2013).

Figura 2 - Peças anatômicas conservadas por criodesidratação.

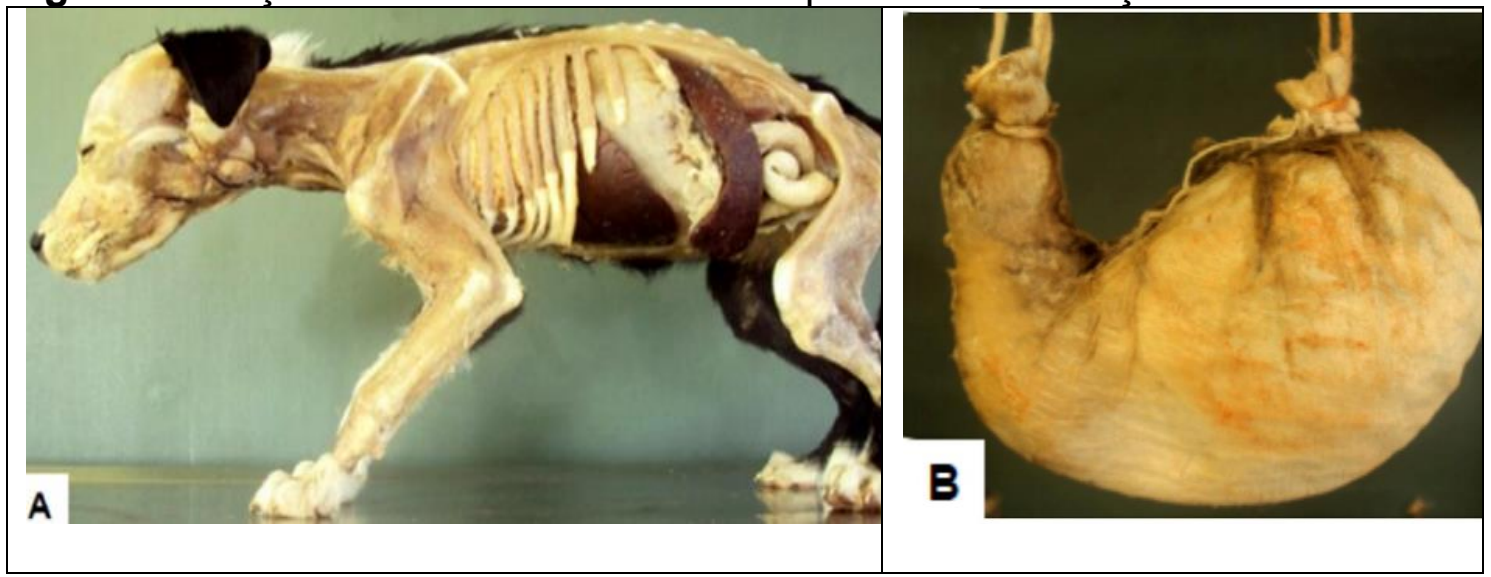

Notas: Em A: Cão após a dissecção de epiderme e anexos, em B: estômago de cão.

Fontes: Cury; Censoni; Ambrosio (2013).

Outra técnica utilizada é a plastinação (Figura 3), procedimento técnico, moderno, que consiste em retirar todos os líquidos e lipídios do corpo com a utilização de acetonas, para substituí-los por polímeros de silicone, resina de epóxi, ou poliéster que, após isto, passam por um processo de endurecimento pela luz, calor ou gases específicos, mantendo a estrutura com os seus detalhes a níveis macroscópicos e histológicos. A técnica de plastinação é realizada basicamente em quatro etapas: fixação, desidratação, impregnação e secagem (RODRIGUES, 2010; GOMEZ; ORTIZ, 2012).

A plastinação foi desenvolvida em 1980 por Gunther Von Hagens e chegou ao Brasil por volta dos anos 90, pelo professor Doutor Aldo Junqueira Rodrigues Júnior, da Faculdade de Medicina da Universidade de São Paulo (OLIVEIRA et al., 2013).

Como vantagens pode-se apresentar o fato de que as peças são conservadas com alta durabilidade e resistência. As características originais são mantidas e o resultado final apresenta-se inodoro, além do fato de dispensar o uso de agentes tóxicos para conservação e manutenção. Ademais, por manter mais fielmente as características dos tecidos, permite uma melhor, identificação das diferentes estruturas e órgãos, o que aumenta a motivação e o entusiasmo do aluno no processo de aprendizagem da anatomia (ANDREOLI et al., 2012; GOMEZ; ORTIZ, 2012). 
Para realização da plastinação é necessário que o profissional tenha um alto nível de especialização nesta técnica e uma infraestrutura adequada para sua realização, o que caracteriza como uma desvantagem ao método (OLIVEIRA et al., 2013; PEREIRA et al., 2013). A plastinação, por ser de alto custo, ainda não é realidade na maioria das universidades como técnica habitual dos laboratórios de Anatomia humana, é mais utilizada na ocasião do preparo de uma peça para exposições e museus (GOMEZ; ORTIZ, 2012).

Figura 3 - Peças anatômicas conservadas por plastinação.

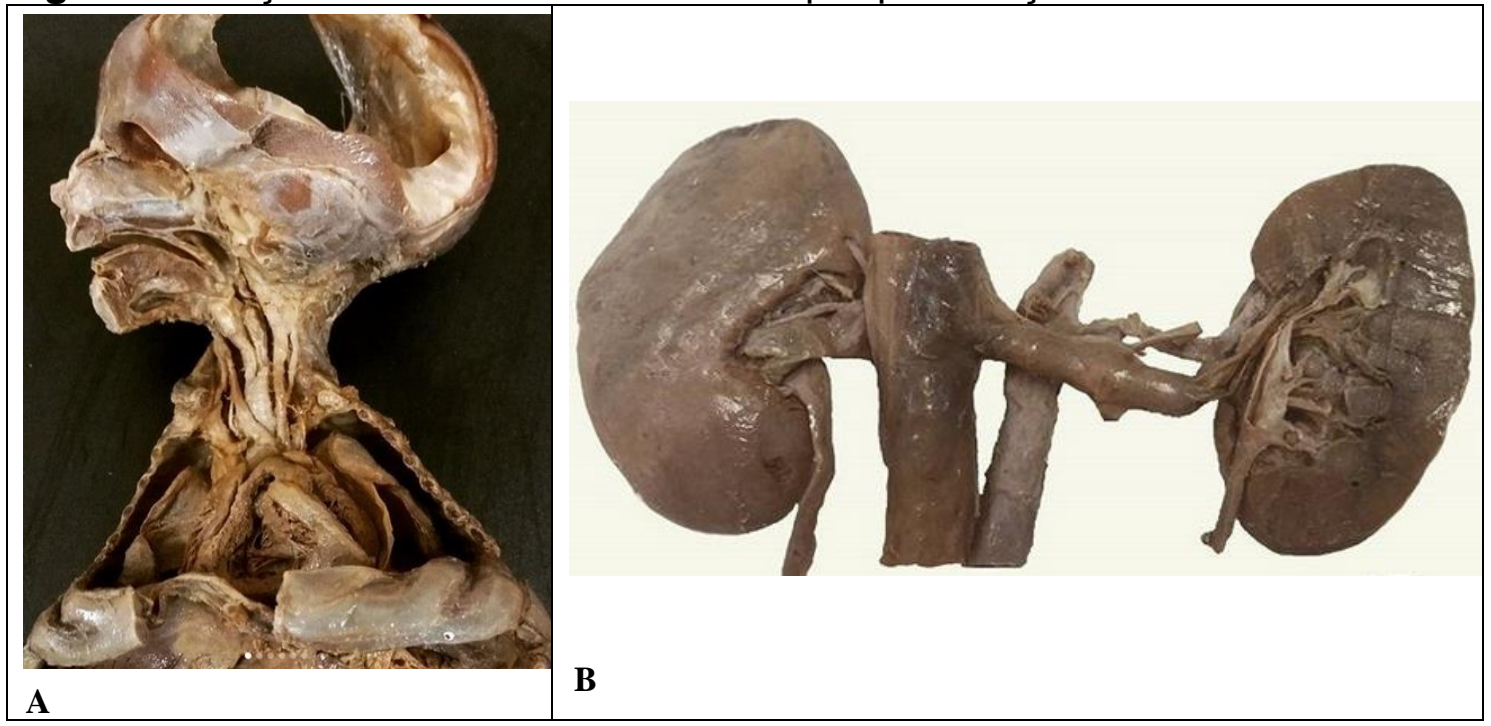

Notas: Em A: tronco de feto humano em B: Rins e vascularização de humanos.

Fonte: UFC (2017).

Os métodos de conservação de tecidos biológicos humanos, formalização, glicerinização, criodesidratação e plastinação podem ser sintetizados quanto as suas vantagens e desvantagens no Quadro 1, bem como uma síntese dos critérios de utilidade da peça anatômica, custo de preparação, manutenção, tempo de preparo, durabilidade e toxicidade que estão apontadas no Quadro 2.

De acordo com Rodrigues (2010), entre os fixadores mais comumente utilizados no Brasil para fins de estudo, tanto da anatomia humana quanto da animal, estão o formol e a glicerina. Estudos evidenciam que $96 \%$ das faculdades de medicina do Brasil utilizam cadáveres humanos nas suas aulas práticas de anatomia, destas, $83,3 \%$ fazem uso da técnica de formolização e $56,4 \%$ da técnica de glicerinização, constata-se um predomínio do uso da formolização em todas as regiões do país. Porém na região Centro-Oeste do Brasil, 60,7\% das faculdades que utilizam a formolização pretendem mudar o método de conservação, para glicerinização, o principal motivo da busca por esta mudança é a insalubridade do formol (SILVA et al., 2016). O ideal é que as instituições que visam aderir à técnica de glicerinização façam a substituição gradativa, para que aos poucos todas, ou a maioria das peças anatômicas, sejam conservadas em glicerina (CURY; CENSONI; AMBROSIO, 2013). 
Quadro 1 - Comparação entre as vantagens e desvantagens de alguns métodos de conservação de tecidos biológicos utilizados na conservação de peças anatômicas.

\begin{tabular}{|l|l|l|}
\hline \multicolumn{1}{|c|}{ TÉCNICA } & \multicolumn{1}{|c|}{ VANTAGENS } & \multicolumn{1}{c|}{ DESVANTAGENS } \\
\hline Formolização & $\begin{array}{l}\text { Baixo custo, facilidade de } \\
\text { realização }\end{array}$ & $\begin{array}{l}\text { Odor, toxicidade, } \\
\text { deterioração, conservação } \\
\text { em solução, necessidade } \\
\text { de manutenção }\end{array}$ \\
\hline Glicerinização & $\begin{array}{l}\text { Leveza, alta durabilidade, } \\
\text { inodora, atóxica }\end{array}$ & $\begin{array}{l}\text { Conservação em solução, } \\
\text { necessidade de } \\
\text { manutenção }\end{array}$ \\
\hline Criodesidratação & $\begin{array}{l}\text { Leveza, baixo custo, dispensa } \\
\text { solução conservadora, inodora, } \\
\text { sem manutenção }\end{array}$ & $\begin{array}{l}\text { Fragilidade, corrosão, } \\
\text { pouca mobilidade na peça }\end{array}$ \\
\hline Plastinação & $\begin{array}{l}\text { Alta resistência e durabilidade, } \\
\text { características originais } \\
\text { mantidas, inodora, sem } \\
\text { manutenção }\end{array}$ & $\begin{array}{l}\text { Alto custo, técnica de difícil } \\
\text { realização }\end{array}$ \\
\hline
\end{tabular}

Fonte: os autores.

Quadro 2 - Comparação entre as características principais de alguns métodos de conservação de tecidos biológicos utilizados na conservação de peças anatômicas.

\begin{tabular}{|l|c|c|c|c|}
\hline \multicolumn{1}{|c|}{ TÉCNICA } & Formolização & Glicerinação & Criodesidratação & Plastinação \\
\hline $\begin{array}{l}\text { Utilização } \\
\text { para estudo }\end{array}$ & Amplo & Amplo & Pouco & Restrito \\
\hline Durabilidade & Média & Média & Baixa & Alta \\
\hline Toxicidade & Alta & Baixa & Baixa & Baixa \\
\hline Custo & Baixo & Moderado & Baixo & Alto \\
\hline Manutenção & Simples & Simples & Não tem & Não tem \\
\hline $\begin{array}{l}\text { Tempo de } \\
\text { Preparo }\end{array}$ & Rápido & Rápido & Demorado & Demorado \\
\hline
\end{tabular}

Fonte: os autores.

Em um estudo realizado por Spaziani et al., (2016) com alunos da faculdade de Medicina da Unicastelo em Fernandópolis - São Paulo, evidenciou que $82,85 \%$ destes preferem realizar o estudo da anatomia com o uso de peças conservadas em glicerina pelo fato de não irritar as mucosas e a conjuntiva ocular durante o estudo. A glicerina apresenta-se em uma substância para conservação inodora que não irrita as mucosas, não é carcinogênica e, se comparada ao formol, seu nível de contaminação ambiental é relativamente mais baixo (RODRIGUES, 2010; KARAM, 2016).

Para as instituições, um fato a ser considerado é a manutenção das peças anatômicas na técnica de conservação escolhida. A glicerinização exige reposição do agente químico menos frequente que a técnica de formalização. $\mathrm{Na}$ técnica de formalização a reposição do formol ocorre após um tempo de conservação, devido a sua volatilidade, mesmo que não haja utilização do material, e, em caso de uso frequente, o formol deve ser constantemente 
renovado, também devido a passagens frequentes do material em água (CURY; CENSONI; AMBROSIO, 2013; PAIM; TOILLIER; BARTHOLDY, 2017).

Uma alternativa ao custo mais elevado da glicerina pura é a glicerina semipurificada, um produto proveniente da produção de biodiesel que pode ser utilizado como substituta para a glicerina pura, além de contribuir com a preservação do meio ambiente evitando que o biodiesel seja descartado de maneira incorreta. Esta glicerina constitui em um meio viável e menos tóxico para substituição do formaldeído na conservação das peças anatômicas (KRUG et al., 2011; CARVALHO et al., 2013).

Outra opção para fins de estudo da anatomia, com um baixo custo para realização da técnica, é a criodesidratação, uma técnica de fácil realização que não é amplamente utilizada nas instituições, seja por falta de domínio da técnica ou por desconhecimento desta, porém esta técnica também apresenta um excelente custo/benefício, desde que as peças sejam manipuladas corretamente para evitar danos ao material estudado (KREMER; SCHUBERT,; BONFIGLIO, 2011; SILVA et al., 2013).

Quanto à plastinação, esta é mais destinada a exposições e museus, é uma técnica pouco utilizada para fins de estudo em laboratórios de anatomia, devido ao seu alto custo e dificuldade de realização, é uma técnica extremamente criteriosa que deve ser rigorosamente seguida para que a peça tenha o resultado esperado (GOMEZ; ORTIZ, 2012).

Uma pesquisa realizada por Pereira et al. (2013), com 338 estudantes universitários de cursos da área da saúde evidenciou que mais de $64 \%$ destes acadêmicos têm preferência em realizar os estudos com peças anatômicas conservadas por meio da técnica da plastinação. Esta técnica representa uma grande revolução no campo da conservação de peças anatômicas, pois ela permite uma manipulação ampla com uma visualização e análise de diversos órgãos e estruturas anatômicas, o que estimula positivamente o aprendizado no campo da anatomia (GOMEZ; ORTIZ, 2012).

A plastinação ainda é uma técnica muito onerosa quando considerada a realidade da maioria das universidades públicas do nosso país, porém, representa atualmente a melhor técnica quando se avalia todos os benefícios, exceto os custos. Espera-se que, em um futuro próximo, a plastinação possa ser estimulada em relação ao seu uso e ao seu financiamento, para que os laboratórios de anatomia humana do Brasil tenham um material anatômico de qualidade que venha suprir a quantidade de material que tem sido disponibilizado às universidades que sofrem com carência de fornecimento de peças anatômicas.

\section{CONSIDERAÇÕES FINAIS}

Conclui-se que, financeiramente, a melhor técnica para realização da conservação de peças anatômicas para fins de estudo é a formolização, porém, com relação aos demais fatores, a técnica que melhor apresenta uma relação custo/benefício é a glicerinização, apesar de ser uma técnica com um custo pouco mais elevado que a formolização. A glicerinização apresenta maiores vantagens em relação à saúde humana e ao meio ambiente, por ter uma toxicidade consideravelmente menor com relação ao formol. A técnica da 
criodesidratação também consiste em uma alternativa viável ao uso do formaldeído, para isto, ela deve ser mais difundida nas universidades e no meio acadêmico, para que haja um maior conhecimento acerca de sua preparação e conservação. Quanto à plastinação, esta ainda é uma alternativa para exposições de peças em museus, devido ao seu alto custo. Considerando custo de preparação, manutenção, tempo de preparo, durabilidade e toxicidade podese dizer que na maioria dos casos a técnica mais indicada para fins do estudo da anatomia humana ou animal é a técnica da glicerinação.

\section{REFERÊNCIAS}

ANDREOLI, A. T. et. al. O aprimoramento de técnicas de conservação de peças anatômicas: a técnica inovadora de plastinação. Revista EPeQ/Fafibe, 4.ed., p. 81-85, 2012.

AVERSI-FERREIRA, T. A. et al. Practice of dissection as teaching methodology in anatomy for nursing education. Brazilian Journal of Morphological Sciences, v. 26, p. 151-157, 2009.

BAPTISTA, J. S. et al. Influência das políticas brasileiras de expansão universitária no ensino da anatomia humana. O Anatomista, v. 3, n. 1, p. 15-24, 2012.

BRASIL. Casa Civil. Lei no 8501, de 30 de novembro de 1992. Brasília: Casa Civil, 1992.

CARVALHO, K. S. Influência do formol utilizado para conservação de cadáveres na obtenção de DNA nuclear em tecido muscular. 2009. $80 \mathrm{f}$. Dissertação (Mestrado em Biologia Bucal) - Universidade Estadual de Campinas, Piracicaba, 2009.

CARVALHO, Y. K. et al. Avaliação do uso da glicerina proveniente da produção de biodiesel na conservação de peças anatômicas. Pesquisa Veterinária Brasileira, v. 33, n. 1, p. 115-118. 2013.

CURY, F. S.; CENSONI, J. B.; AMBROSIO, C. E. Técnicas anatômicas no ensino da prática de anatomia animal. Pesquisa Veterinária Brasileira, v. 33, n. 5, p. 688-696, 2013.

DANGELO, J. C.; FATTINI, C. A. Anatomia humana sistêmica e segmentar. 3. ed. São Paulo: Atheneu, 2007. 671 p.

GOMEZ, C. A. M.; ORTIZ, J. A. Plastinación: un instrumento complementario para el desarrollo del processo enseñanza-aprendizaje de la anatomia. Revista de Medicina Veterinária, n. 23, p. 111-117, 2012. 
KARAM, R. G. et al. Uso da glicerina para substituição do formaldeído na conservação de peças anatômicas. Pesquisa Veterinária Brasileira, v. 36, n. 7, p. 671-675, 2016.

KREMER, R.; SCHUBERT, J. M.; BONFIGLIO, N. S. Criodesidratação de vísceras do canal alimentar no preparo de peças anatômicas para estudo veterinário. PUBVET, v. 5, n. 13, 2011. Disponível em: https://www.pubvet.com.br/uploads/ed53acb01fa60080aafc71d546eca636.pdf.

Acesso em: 9 set. 2018.

KRUG, L. et al. Conservação de peças anatômicas com glicerina loira. In: I Mostra de Iniciação Científica, 2011. Concórdia. Anais da I Mostra de Iniciação Científica do Instituto Federal Catarinense, Concórdia - Santa Catarina, 2011. Disponível em: http://mic.concordia.ifc.edu.br/wp-content/uploads/sites/30/2017/ 10/MIC109_Conserva\%C3\%A7\%C3\%A3o_de_pe\%C3\%A7as_anat\%C3\%B4mi cas_com_glicerina_loira.pdf. Acesso em: 9 set. 2018.

MELLO, J. M. et al. O laboratório de Anatomia Humana como espaço não formal de ensino. Arquivos do MUDI, v. 14, n. 1a3, p. 19 a 26. Maringá, 2010.

MELO, E. N. de; PINHEIRO, J. T. Procedimentos legais e protocolos para utilização de cadáveres no ensino de anatomia em Pernambuco. Revista Brasileira de Educação Médica, v. 34, n. 2. Rio de Janeiro, 2010.

NATIONAL TOXICOLOGY PROGRAM - NTP. Final Report on Carcinogens: Background Document for Formaldehyde. Department of Health and Human Services, Research Triangle Park, NC, USA. 512p. 2010.

NATIONAL TOXICOLOGY PROGRAM - NTP. Released the $14^{\text {th }}$ Report on Carcinogens. Department of Health and Human Services, Research Triangle Park, NC, USA, 2016.

OLIVEIRA, I. M. et al. Análise de peças anatômicas preservadas com resina de poliéster para estudo em anatomia humana. Revista do Colégio Brasileiro de Cirurgiões, v. 40, n. 1, p. 76-80, 2013.

PAIM, P. dos S.; TOILLIER, S.; BARTHOLDY, L. Comparativo da utilização de formol e glicerina para a conservação dos cadáveres do laboratório de anatomia humana. In: V Salão de Ensino e Extensão, 2014. Universidade Santa Cruz do Sul. Anais do V Salão de Ensino e Extensão. Santa Cruz do Sul, 2014. Disponível em: https://online.unisc.br/acadnet/anais/index.php/salao_ensino_ extensao/article/view/12440. Acesso em: 10 set. 2018

PEREIRA, K. F. et al. Utilização de material plastinado em detrimento aos modelos tradicionais: verificação da predileção de alunos de anatomia humana. Arquivos de Ciências da Saúde UNIPAR, Umuarama, v. 17, n. 2, p. 105-108, 2013. 
QUEIROZ, C. de A. F. O uso de cadáveres humanos como instrumento na construção de conhecimento a partir de uma visão bioética. 2005. $129 \mathrm{f}$. Dissertação (Mestrado em Ciências da Saúde) - Pontifícia Universidade Católica de Goiás, Goiânia, 2005.

RODRIGUES, H. Técnicas Anatômicas. 4 ed. Vitoria: GM Gráfica e Editora, 2010. 269 p.

SILVA E. M. et al. Estudo analítico da técnica de glicerinização empregada para conservação de peças anatômicas: experiência da disciplina de anatomia humana do departamento de morfologia da UniFOA. UniFOA, v. 3, p. 66-69. 2008.

SILVA, G. R. et al. Métodos de conservação de cadáveres humanos utilizados nas faculdades de medicina do Brasil. Revista de Medicina, v. 95, n. 4, p. 156161. São Paulo, 2016.

SILVA, S. R. S. B. et al. Preparo de peças anatômicas através do método de criodesidratação. In: XIII Jornada de Ensino, Pesquisa e Extensão, 2013. Recife. Anais da XIII Jornada de Ensino, Pesquisa e Extensão, Recife - Pernambuco, 2013. Disponível em: http://www.eventosufrpe.com.br/2013/cd/resumos/R13951.pdf. Acesso em: 10 set. 2018.

SOUZA, S. C. Anatomia: aspectos históricos e evolução. Revista de Ciências Médicas e Biológicas, v. 10, n. 1, p. 3-6, 2011.

SPAZIANI, A. O. et al. Formalização e glicerinização: estudo de preferência de técnica de conservação anatômica por acadêmicos. Archives of Health Investigation, v. 5, n. 3, 2016.

TAVANO, P. T.; OLIVEIRA, M. C. de. Surgimento e desenvolvimento da ciência anatômica. Anhanguera Educacional: Anuário da Produção Acadêmica Docente. v. 2, n. 3, p. 73-84, 2008.

UNIVERSIDADE FEDERAL DO CEARÁ - UFC. Departamento de Morfologia. 2017. Disponível em: http://www.anatomia.ufc.br/index.php/plastinacao. Acesso em: 4 set 2018.

VIEGAS, S. et al. Genotoxic effects in occupational exposure to formaldehyde: a study in anatomy and pathology laboratories and formaldehyde-resins production. Journal of Occupational Medicine and Toxicology, v. 5, n. 1 p. 25, 2010. 